\title{
The Role of Tissue Factor and Factor VIla in Hemostasis
}

\author{
Nigel Mackman, PhD \\ From the Division of Hematology/Oncology, Department of Medicine, University of North Carolina \\ at Chapel Hill, Chapel Hill, North Carolina.
}

\begin{abstract}
Tissue factor (TF) is a transmembrane receptor for Factor VII/VIIa (FVII/VIIa). It is constitutively expressed by cells surrounding blood vessels. The endothelium physically separates this potent "activator" from its circulating ligand FVII/FVIIa and prevents inappropriate activation of the clotting cascade. Breakage of the endothelial barrier leads to exposure of extravascular TF and rapid activation of the clotting cascade. TF is also expressed in certain tissues, such as the heart and brain, and provides additional hemostatic protection to these tissues. Small amounts of TF are also present in blood in the form of microparticles, which are small membrane vesicles derived from activated and apoptotic cells. Levels of microparticle TF increase in a variety of diseases, such as sepsis and cancer, and this so-called "blood-borne" TF may contribute to thrombosis associated with these diseases. Recombinant FVIIa has been developed as an effective hemostatic drug for the treatment of hemophilia patients with inhibitory antibodies. In addition, it is used for patients with bleeding that do not respond to conventional therapy. However, the mechanism by which recombinant FVIIa restores hemostasis has not been clearly defined. In conclusion, the TF:FVIIa complex is essential for hemostasis and recombinant FVIIa is an effective hemostatic drug.
\end{abstract}

The coagulation system has been historically divided into three pathways: the extrinsic, intrinsic, and common pathways (Fig. 1).1-3 The tissue factor (TF): Factor VII/VIIa (FVII/ FVIIa) complex was called the "extrinsic" pathway because an exogenous agent (i.e., TF) was required for activation of the clotting factors in plasma. The TF:FVIIa complex is the key initiator of the coagulation protease cascade and activates both FIX to FIXa and FX to FXa. This leads to the formation of low amounts of thrombin, which activates the cofactors FV and FVIII. The prothrombin time is determined by adding exogenous TF to plasma and is used to assess the activity of the extrinsic pathway. Components of the "intrinsic" pathway (FXII, FXI, FIX, and FVIII) are all present in blood. ${ }^{4}$ The tenase complex (FVIIIa:FIXa) plays a key role in amplifying the clotting cascade by activating FX to FXa. The activated partial prothrombin time uses kaolin or other negatively charged substances to activate FXII and is used to assess the activity of the intrinsic pathway. The prothrombinase complex (FVa:FXa) and thrombin are referred to as the common pathway. The prothrombinase complex activates prothrombin to thrombin, which is the central protease of the clotting cascade. Thrombin cleaves fibrinogen into soluble fibrin monomers that polymerize. Thrombin also activates the transglutaminase FXIII to FXIIIa that in turn cross-links soluble fibrin monomers into a fibrin matrix. Finally, thrombin activates platelets by cleavage of protease activated receptors.5

\footnotetext{
Copyright $\odot 2009$ International Anesthesia Research Society

Address correspondence and reprint requests to Nigel Mackman, PhD, Division of Hematology/Oncology, Department of Medicine, University of North Carolina at Chapel Hill, 915 Mary Ellen Jones, Campus Box 7035, Chapel Hill, NC 27599-7035. nmackman@med.unc.edu.

The author has no conflict of interest related to this review.
} 
The coagulation cascade is regulated by several anticoagulants. A kunitz-type serine protease inhibitor called TF pathway inhibitor inhibits the TF:FVIIa complex by forming a quaternary complex with FXa. ${ }^{6}$ Protein $\mathrm{C}$ is converted to activated protein $\mathrm{C}$ by a thrombinthrombomodulin complex located on the surface of endothelial cells. ${ }^{7}$ Activated protein $\mathrm{C}$ in association with its cofactor protein S cleaves and inactivates the cofactors FV and FVIII. The primary target of the anticoagulant protein antithrombin is thrombin, although it can also inactivate other coagulation proteases in the cascade, including FIXa, FXa, FXIa, and FXIIa. 8

\section{TF IS ESSENTIAL FOR HEMOSTASIS}

TF is expressed by vascular smooth muscle cells, pericytes, and adventitial fibroblasts within the vessel wall and surrounding blood vessels (Fig. 2) ${ }^{9,10}$ An early study by Drake et al. ${ }^{9}$ proposed that TF forms "a hemostatic envelope" around blood vessels. Disruption of the endothelial barrier allows binding of plasma FVII/FVIIa to extravascular TF and activation of the clotting cascade. More recently, however, it was found that TF expressed around blood vessels is bound with FVII in the absence of injury, ${ }^{11}$ which is presumably derived from the plasma. In contrast, TF in squamous epithelium in the skin did not contain FVII. These data suggest that the TF:FVII complex is preformed around blood vessels in the absence of injury, which would allow a more rapid activation of clotting after injury.

Inactivation of the TF gene in mice revealed an essential role for TF in hemostasis. $12^{-} 14 \mathrm{TF}$ deficiency was associated with death during embryonic development and in the perinatal period. Similarly, mice lacking FVII die in the perinatal period.15 Humans can survive with very low levels of FVII but apparently not without TF.16 However, it is difficult to measure levels of TF because it is primarily expressed in tissues in normal individuals. In contrast, the intrinsic pathway may be viewed as important but not "essential" for life in both humans and mice. For instance, humans and mice lacking FXII have no hemostatic defects. Humans lacking FXI generally have mild hemostatic defects, whereas mice lacking FXI have no hemostatic defects. The most common deficiencies in the clotting system in humans are FVIII (Hemophilia A) and FIX (Hemophilia B).4 Both of these deficiencies are associated with hemostatic defects, particularly in the joints and skeletal muscle. Mice lacking FVIII or FIX survive but exhibit excessive bleeding after hemostatic challenge, such as tail transection.17 These results are consistent with the notion that the tenase complex (FVIIIa:FIXa) amplifies the clotting cascade and thus plays an important role in hemostasis. 4

\section{IDLING OF THE CLOTTING SYSTEM IN NORMAL INDIVIDUALS}

Several studies have shown that there is a low basal level of activation or "idling" of the clotting system in normal individuals, which would allow a more rapid response to vessel injury. This may be initiated by a continuous low level activation of coagulation or from subclinical vascular injuries (see later). Evidence for idling of the clotting cascade came from the measurement of activation peptides. For instance, the final step of the clotting cascade is thrombin cleavage of fibrinogen, which leads to the release of two peptides called Fibrinopeptide A and

Fibrinopeptide B. These peptides have a very short half-life in plasma of around 3-5 min. In 1974, Nossel et al.18 measured the level of Fibrinopeptide A in plasma in 30 normal men and found mean levels of $0.5 \mathrm{ng} / \mathrm{mL}$. The fact that this short-lived peptide could be detected in healthy individuals suggested an idling of the clotting cascade. Further support for this notion was provided by Bauer et al.19,20 who showed that normal individuals have plasma concentrations of the FX and FIX activation peptides of $66.4 \mathrm{pmol} / \mathrm{L}$ (range, 39.4-112 pmol/ $\mathrm{L}$ ) and $203 \mathrm{pmol} / \mathrm{L}$ (range, 131-284 pmol/L), respectively. The half-life of the FX activation peptide was determined to be $<30 \mathrm{~min}$. What pathway is responsible for the basal activation of the clotting cascade? This question was addressed by analyzing the levels of FX and FIX 
activation peptides in individuals with deficiencies in either the extrinsic (FVII) or intrinsic pathways (FXI). A deficiency in FVII was associated with a decrease in the levels of FX and FIX activation peptides, whereas a deficiency in FXI of the intrinsic pathway did not change the levels of these peptides. 19,20 Moreover, administration of an inhibitory anti-TF antibody into chimpanzees reduced the basal levels of both the FIX and FX activation peptides.21 Levels of thrombin-antithrombin complex in plasma can also be used to monitor basal coagulation in humans and mice. We found that mice genetically engineered to express very low levels of TF have lower levels of basal thrombin-anthrombin complex.22 These results indicate that the extrinsic pathway is responsible for idling of the clotting cascade in normal individuals and in mice.

How does the TF:FVIIa complex participate in the idling of the clotting cascade? Two models can be proposed: one involving extravascular TF and the other involving intravascular TF (Fig. 3). However, these models are not mutually exclusive. In the "extravascular TF" model, leakage of clotting factors from the blood into the vessel wall or after subclinical vessel injury is proposed to generate low levels of thrombin (Fig. 3A). Studies by Hoffman et al. ${ }^{11}$ described earlier showed that extravascular TF is bound with FVII. Indeed, one study measured the levels of different clotting factors in peripheral afferent lymph as a monitor of the degree of leakage from the blood. As expected, levels of the smaller clotting proteins (FVII, FIX, FX, and prothrombin) in the lymph were higher than the larger proteins, such as FV and fibrinogen.

${ }^{23}$ One can speculate that the presence of these clotting factors, together with TF in the vessel wall, may generate low levels of thrombin even in the absence of the cofactors FV and FVIII. Diffusion of this thrombin back into blood would bring it into contact with fibrinogen.

Alternatively, subclinical vessel injury would allow access of plasma clotting factors to extravascular TF. In the "intravascular TF" model, low levels of TF in the blood itself, socalled circulating TF, would be responsible for the idling of the clotting cascade (Fig. 3B). ${ }^{24}$ Circulating monocytes have been shown to express low levels of TF and this may be the major source of intravascular TF that leads to basal coagulation. ${ }^{25}$ It should be noted that this concept is controversial because some investigators believe that there is no functional TF in the blood of normal individuals. ${ }^{26,27}$ Importantly, wild-type mice containing bone marrow from low TF mice had reduced levels of basal thrombin-antithrombin complex, suggesting that TF

expression by hematopoietic cells contributes to the idling of the clotting cascade. Regardless of the source, these results indicate that the TF:FVIIa complex plays a key role in idling of the clotting cascade.

\section{TF IS EXPRESSED IN A TISSUE-SPECIFIC MANNER}

A classic view of the clotting system is that it functions in a similar manner in all tissues, but recent studies indicate that this is not the case. For instance, TF is expressed at different levels in different organs in both humans and mice. High levels of TF are present in the brain, lung, heart, uterus, placenta, and testis, whereas low to undetectable levels are present in skeletal muscle, joints, and liver (Fig. 4). ${ }^{9,28,29}$ We speculated that this TF provides additional hemostatic protection to vital tissues. However, this notion was difficult to test. Fortunately, we engineered mice that expressed low levels of TF, so-called "low TF mice." Low TF mice express low levels of human TF under the control of the human TF promoter ${ }^{30}$ This promoter directs a cell type-specific pattern of TF expression that is similar to wild-type mice and is sufficient for survival of embryos and general hemostasis in adult mice. However, we observed tissue-specific hemostatic defects in older low-TF mice, including hemorrhages in the lungs, heart, brain, uterus, placenta, and testis ${ }^{31-34}$ Similar hemostatic defects were observed in mice engineered to express low levels of FVII. ${ }^{15,33}$ This indicated that a deficiency in the TF:FVIIa complex was associated with tissue-specific hemostatic defects in mice. 
Childbirth is a major hemostatic challenge because the placenta must be separated from the uterine wall. As noted earlier, high levels of TF are found in the uterus. We found that TF plays a critical role in uterine hemostasis because we observed a high frequency of fatal hemorrhages of low TF female mice postpartum. ${ }^{31}$ Surprisingly, mice deficient in components of the intrinsic pathway (FVIII or FIX) have normal postpartum hemostasis. Interestingly, a pharmacological approach also led to tissue-specific hemorrhage in mice. Administration of an inhibitory anti-human TF antibody to mice that expressed human TF induced bleeding in the lung, heart, brain, and testis ${ }^{35,} 36$ What about tissues that have low levels of TF? As mentioned earlier, individuals with hemophilia A or B are prone to hemorrhages in joints and skeletal muscle, which are both sites with low levels of TF. This strongly suggests that hemostasis in skeletal muscle and joints is more dependent on the intrinsic pathway rather than the extrinsic pathway (Fig. 4). Taken together, these observations support our proposal that $\mathrm{TF}$ expression in certain tissues provide additional hemostatic protection.

The bleeding sites in low TF mice and low FVII mice (heart and lung) are generally in tissues that are mechanically active. Similarly, bleeding in Hemophilia A and Hemophilia B patients is more common in joints and skeletal muscle. We speculate that blood vessels in these tissues are injured by the mechanical activity of the tissue. In individuals with normal hemostasis, these injuries result in small hemorrhages with rapid repair. In contrast, joint bleeds in individuals with hemophilia lead to inflammation and eventually hemophilic arthropathy. We have found that bleeding into the hearts of low TF mice leads to inflammation and fibrosis. Therefore, the extrinsic and intrinsic pathways of blood coagulation are particularly important for maintaining hemostasis in mechanically active tissues.

\section{RECOMBINANT FVIIA AS A HEMOSTATIC DRUG}

Recombinant FVIIa (rFVIIa) has been developed as a hemostatic drug for the treatment of hemophilia patients with inhibitors.37 It is used in these patients in acute settings to ensure hemostasis during major surgery and to stop serious bleeds. rFVIIa has also been used in secondary prophylaxis for patients with severe hemophilia. Daily treatment of patients with rFVIIa during a 3-mo observation period reduced the number of hemorrhagic episodes. 38 Given the short half-life (approximately $2 \mathrm{~h}$ ) of rFVIIa, it seems surprising that a daily dose of rFVIIa was able to maintain hemostasis. One possibility is that rFVIIa may diffuse out of the vasculature and bind to extravascular TF where it would increase the amount of the TF:FVIIa complex and thus increase thrombin generation. This idea is consistent with the observation that endogenous FVII binds to extravascular TF. Regardless of the mechanism, these clinical results indicate that supplementation of the extrinsic pathway with recombinant FVIIa can restore hemostasis in individuals with defects in the intrinsic pathway.

rFVIIa has also been used "off-label" to treat bleeding in patients with platelet defects and in normal individuals with uncontrolled bleeding because of surgery, trauma, or child birth. A summary of many studies indicated that the thrombotic complications associated with the use of rFVIIa are in the range of $1 \%-2 \%$, suggesting that it was a safe drug 39,40 These results led to the suggestion that rVIIa could be used as a general hemostatic drug to treat a range of bleeding problems. ${ }^{39}, 41$ However, other investigators do not support this conclusion and recommend randomized clinical trials to assess the efficacy and safety of FVIIa in patients without hemophilia.42,43 Recently, the efficacy and safety of rFVIIa was assessed in patients with acute intracerebral hemorrhage. ${ }^{44}$ Unfortunately, despite a reduction in bleeding the low $(20 \mu \mathrm{g} / \mathrm{kg})$ and high $(80 \mu \mathrm{g} / \mathrm{kg})$ doses of rFVIIa did not improve clinical outcome. Moreover, the thromboembolic adverse events in arteries for the high-dose patients were more than double the placebo group (9\% vs 4\%). In a mouse model, overexpression of FVIIa led to thrombosis and premature death of the mice. ${ }^{45}$ Interestingly, thrombosis was most common in the heart and lung, which are sites of high TF expression. These results suggest that further studies are 
required to understand the causes of the thromboembolic events associated with the administration of rFVIIa.

The mechanism of action of rFVIIa has not been clearly established and high doses are required to restore hemostasis. It should be noted that the presence of TF enhances the activity of FVIIa for its substrate FX by about 1000-fold, so very low levels of TF would have a dramatic effect on the activity of rFVIIa. An early study showed that FVIIa can activate FX on a negatively charged phospholipid surface independent of TF. ${ }^{46}$ This observation was extended by Hoffman et al. ${ }^{47}$ who proposed that therapeutic doses of rFVIIa bind to phosphatidylserine exposed on the surface of activated platelets and activates FX in a TF-independent manner ${ }^{41}$ Other investigators suggest that $\mathrm{rFVII}$ requires TF to restore hemostasis. An early study suggested that high doses of rFVIIa are required because it needs to compete with zymogen FVII for binding to TF and increase the formation of an active TF:FVIIa complex. ${ }^{48}$ In support of this idea, one study showed that zymogen FVII delayed thrombin generation in a TF-dependent model of hemophilia, and this inhibition could be overcome by therapeutic doses of FVIIa. 49-51 Further studies are required to clarify how rFVIIa restores hemostasis in patients with a deficiency in the intrinsic pathway or with uncontrolled bleeding.

\section{CONCLUSIONS}

The TF:FVIIa complex is essential for hemostasis. TF expression in certain tissues provides additional hemostatic protection. Supplementation of the extrinsic pathway in the form of rFVIIa can be used to correct hemostatic defects in individuals with deficiencies in the intrinsic pathway. However, the mechanism of action of rFVIIa is still not fully understood. Although rFVIIa has been used off-label to treat bleeding in patients without hemophilia, there is a risk of thrombosis. Further studies are needed to improve the efficacy and safety of hemostatic drugs used to treat bleeding.

\section{Acknowledgments}

The author thanks Drs. N. Key, R. Kasthuri, and D. Monroe for providing comments on the manuscript and Dr. M. Hoffman for the picture of TF staining in a blood vessel.

Supported by NIH.

\section{REFERENCES}

1. Davie EW, Fujikawa K, Kisiel W. The coagulation cascade: initiation, maintenance, and regulation. Biochemistry 1991;30:10363-10370. [PubMed: 1931959]

2. Edgington TS, Mackman N, Brand K, Ruf W. The structural biology of expression and function of tissue factor. Thromb Haemost 1991;66:67-79. [PubMed: 1833852]

3. Nemerson Y. Tissue factor and hemostasis. Blood 1988;71:1-8. [PubMed: 3275472]

4. Gilani D, Renne T. Intrinsic pathway of coagulation and arterial thrombosis. Arterioscler Thromb Vasc Biol 2007:2507-2513. [PubMed: 17916770]

5. Coughlin SR. Thrombin signalling and protease-activated receptors. Nature 2000;407:258-264. [PubMed: 11001069]

6. Broze GJ Jr, Girard TJ, Novotny WF. Regulation of coagulation by a multivalent Kunitz-type inhibitor. Biochemistry 1990;29:7539-7546. [PubMed: 2271516]

7. Esmon CT. The protein C anticoagulant pathway. Arterioscler Thromb 1992;12:135-145. [PubMed: 1311945]

8. Stein B, Baldwin AS Jr, Ballard DW, Greene WC, Angel P, Herrlich P. Cross-coupling of the NF- $\kappa$ B p65 and Fos/Jun transcription factors produces potentiated biological function. EMBO J 1993;12:3879-3891. [PubMed: 8404856] 
9. Drake TA, Morrissey JH, Edgington TS. Selective cellular expression of tissue factor in human tissues. Implications for disorders of hemostasis and thrombosis. Am J Pathol 1989;134:1087-1097. [PubMed: 2719077]

10. Fleck RA, Rao LVM, Rapaport SI, Varki N. Localization of human tissue factor antigen by immunostaining with monospecific, polyclonal anti-human tissue factor antibody. Thromb Res 1990;57:765-781.

11. Hoffman M, Colina CM, McDonald AG, Arepally G, Pedersen L, Monroe DM. Tissue factor around dermal vessels has been bound factor VII in the absence of injury. $\mathrm{J}$ of Thrombosis and Hemostasis 2007:1403-1408.

12. Carmeliet P, Mackman N, Moons L, Luther T, Gressens P, Van Vlaenderen I, Demunck H, Kasper M, Breier G, Evrard P, Müller M, Risau W, Edgington T, Collen D. Role of tissue factor in embryonic blood vessel development. Nature 1996;383:73-75. [PubMed: 8779717]

13. Bugge TH, Xiao Q, Kombrinck KW, Flick MJ, Holmback K, Danton MJS, Colbert MC, Witte DP, Fujikawa K, Davie EW, Degen JL. Fatal embryonic bleeding events in mice lacking tissue factor, the cell-associated initiator of blood coagulation. Proc Natl Acad Sci USA 1996;93:6258-6263. [PubMed: 8692802]

14. Toomey JR, Kratzer KE, Lasky NM, Stanton JJ, Broze GJ Jr. Targeted disruption of the murine tissue factor gene results in embryonic lethality. Blood 1996;88:1583-1587. [PubMed: 8781413]

15. Rosen ED, Xu H, Liang Z, Martin JA, Suckow M, Castellino FJ. Generation of genetically-altered mice producing very low levels of coagulation factor VII. Thromb Haemost 2005;94:493-497. [PubMed: 16268461]

16. Tuddenham EGD, Pemberton S, Cooper DN. Inherited factor VII deficiency: genetics and molecular pathology. Thromb Haemost 1995;74:313-321. [PubMed: 8578478]

17. Mackman N. Role of tissue factor in hemostasis, thrombosis, and vascular development. Arterioscler Thromb Vasc Biol 2004;24:1015-1022. [PubMed: 15117736]

18. Nossel HL, Yudelman I, Canfield RE, Butler VP, Spanondis K, Wilner GD, Qureshi GD. Measurement of fibrinopeptide A in human blood. J Clin Invest 1974;54:43-53. [PubMed: 4600045]

19. Bauer KA, Kass BL, Cate HT, Hawiger JJ, Roseberg RD. Factor IX is activated in vivo by the tissue factor mechanism. Blood 1990;76:731-736. [PubMed: 2383653]

20. Bauer KA, Kass BL, ten Cate H, Bednarek MA, Hawiger JJ, Rosenberg RD. Detection of factor X activation in humans. Blood 1989;74:2007-2015. [PubMed: 2804345]

21. Cate HT, Bauer KA, Levi M, Edgington TS, Sublett RD, Barzegar S, Kass BL, Rosenberg RD. The activation of factor $\mathrm{X}$ and prothrombin by recombinant factor VIIa in vivo is mediated by tissue factor. J Clin Invest 1993;92:1207-1212. [PubMed: 8376580]

22. Pawlinski R, Pedersen B, Schabbauer G, Tencati M, Holscher T, Boisvert W, Andrade-Gordon P, Frank RD, Mackman N. Role of tissue factor and protease activated receptors in a mouse model of endotoxemia. Blood 2004;103:1342-1347. [PubMed: 14576054]

23. Miller GJ, Howarth DJ, Attfield JC, Cooke CJ, Nanjee MN, Olszewski WL, Morrissey JH, Miller NE. Haemostatic factors in human peripheral afferent lymph. Thromb Haemost 2000;83:427-432. [PubMed: 10744149]

24. Jesty J, Beltrami E. Positive feedback of coagulation their role in threshold regulation. Arterioscler Thromb Vasc Biol 2005;25:2463-2469. [PubMed: 16179597]

25. Osterud B, Bjorklid E. Sources of tissue factor. Semin Thromb Hemost 2006;32:11-23. [PubMed: 16479458]

26. Butenas S, Bouchard BA, Brummel-Ziedins KE, Parhami-Seren B, Mann KG. Tissue factor activity in whole blood. Blood 2005;105:2764-2770. [PubMed: 15604222]

27. Butenas S, Mann KG. Active tissue factor in blood? Nat Med 2004;10:1155-1156. [PubMed: 15516902]

28. Mackman N, Sawdey MS, Keeton MR, Loskutoff DJ. Murine tissue factor gene expression in vivo: tissue and cell specificity and regulation by lipopolysaccharide. Am J Pathol 1993;143:76-84. [PubMed: 8317556]

29. Hartzell S, Ryder K, Lanahan A, Lau LF, Nathans D. A growth factor-responsive gene of murine BALB/c 3T3 cells encodes a protein homologous to human tissue factor. Mol Cell Biol 1989;9:25672573. [PubMed: 2761539] 
30. Parry GCN, Erlich JH, Carmeliet P, Luther T, Mackman N. Low levels of tissue factor are compatible with development and hemostasis in mice. J Clin Invest 1998;101:560-569. [PubMed: 9449688]

31. Erlich JH, Parry GCN, Fearns C, Muller M, Carmeliet P, Luther T, Mackman N. Tissue factor is required for uterine hemostasis and maintenance of the placental labyrinth during gestation. PNAS 1999;96:8138-8143. [PubMed: 10393961]

32. Pedersen B, Holscher T, Sato Y, Pawlinski R, Mackman N. A balance between tissue factor and tissue factor pathway inhibitor is required for embryonic development and hemostasis in adult mice. Blood 2005;105:1734-1741. [PubMed: 15494427]

33. Pawlinski R, Fernandes A, Kehrle B, Pedersen B, Parry G, Erlich J, Pyo R, Gutstein D, Zhang J, Castellino F, Melis E, Carmeliet P, Baretton G, Luther T, Taubman M, Rosen E, Mackman N. Tissue factor deficiency causes cardiac fibrosis and left ventricular dysfunction. Proc Natl Acad Sci USA 2002;99:15333-15338. [PubMed: 12426405]

34. Pawlinski R, Tencati M, Holscher T, Pedersen B, Voet T, Tilley RE, Marynen P, Mackman N. Role of cardiac myocyte tissue factor in heart hemostasis. J Thromb Haemost 2007;5:1693-1700. [PubMed: 17663739]

35. Snyder LA, Rudnick KA, Tawadros R, Volk A, Tam SH, Anderson GM, Bugelski PJ, Yang J. Expression of human tissue factor under the control of the mouse tissue factor promoter mediates normal hemostasis in knock-in mice. J Thromb Haemost 2007;6:306-314. [PubMed: 18005233]

36. Mackman N. Tissue-specific hemostasis: role of tissue factor. J Thromb Haemost 2008;6:303-305. [PubMed: 18088348]

37. Hedner U. NovoSeven as a universal haemostatic agent. Blood Coagul Fibrinolysis 2000;11:S107S111. [PubMed: 10850574]

38. Hedner U. Potential role of recombinant factor FVIIa in prophylaxis in severe hemophilia patients with inhibitors. J Thromb Haemost 2006;4:2498-2500. [PubMed: 16907841]

39. Roberts HR. Recombinant factor VIIa: a general hemostatic agent? Yes. J Thromb Haemost 2004;2:1691-1694. [PubMed: 15456475]

40. Levi M, Peters M, Buller HR. Efficacy and safety of recombinant factor VIIa for treatment of severe bleeding: a systematic review. Crit Care Clin 2005;33:883-890.

41. Hedner U. Mechanism of Action of factor VIIa in the treatment of coagulopathies. Semin Thromb Hemost 2006;32:77-85. [PubMed: 16673269]

42. Levi M. Recombinant factor VIIa: a general hemostatic agent? Not yet. J Thromb Haemost 2004;2:1695-1697. [PubMed: 15456476]

43. O’Connell KA, Wood JJ, Wise RP, Lozier JN, Braun M. Thromboembolic adverse events after use of recombinant human coagulation factor VIIa. JAMA 2006;295:293-298. [PubMed: 16418464]

44. Mayer SA, Brun NC, Begtrup K, Broderick J, Davis S, Diringer MN, Skolnick BE, Steiner T. Efficacy and Safety of Recombinant Activated Factor VII for Acute Intracerebral Hemorrhage. N Engl J Med 2008;358:2127-2137. [PubMed: 18480205]

45. Aljamali M, Margaritis P, Schlachterman A, Tai SJ, Roy E, Bunte R, Camire R, High KA. Long-term expression of murine activated factor VII is safe, but elevated levels cause premature mortality. $\mathrm{J}$ Clin Invest 2008;118:1825-1834. [PubMed: 18398505]

46. Bom VJJ, Bertina RM. The contributions of $\mathrm{Ca}^{2+}$, phospholipids and tissue-factor apoprotein to the activation of human blood-coagulation factor X by activated factor VII. Biochem J 1990;265:327336. [PubMed: 2302175]

47. Hoffman M, Monroe DM III, Roberts HR. Activated factor VII activates factors IX and X on the surface of activated platelets: thoughts on the mechanism of action of high-dose activated factor VII. Blood Coagul Fibrinolysis 1998;9:S61-S65. S61-S65. [PubMed: 9819030]

48. Rao LV, Rapaport SI. Factor VIIa-catalyzed activation of factor X independent of tissue factor: its possible significance for control of hemophilic bleeding by infused factor VIIa. Blood 1990;75:10691073. [PubMed: 2306514]

49. van't Veer C, Mann KG. The regulation of the factor VII-dependent coagulation pathway: rationale for the effectiveness of recombinant factor VIIa in refractory bleeding disorders. Semin Thromb Hemost 2000;26:367-372. [PubMed: 11092210]

50. Butenas S, Brummel KE, Branda RF, Paradis SG, Mann KG. Mechanism of factor VIIa-dependent coagulation in hemophilia blood. Blood 2002;99:923-930. [PubMed: 11806995] 
51. Butenas S, Brummel KE, Bouchard BA, Mann KG. How factor VIIa works in hemophilia. J Thromb Haemost 2003;1:1158-1160. [PubMed: 12871314] 


\section{Vessel Wall}

\section{TF Extrinsic}

FXIla.

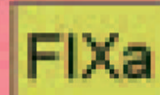

Intrinsic
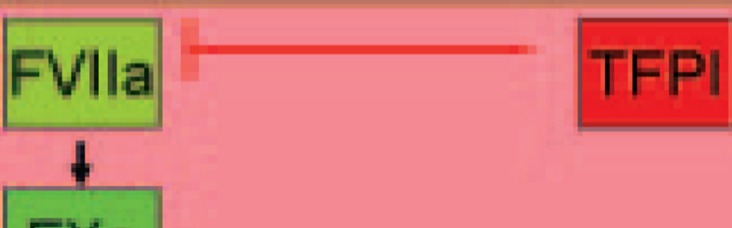

FXa

FVa Common

1

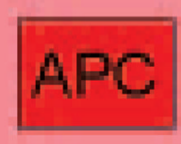

Blood

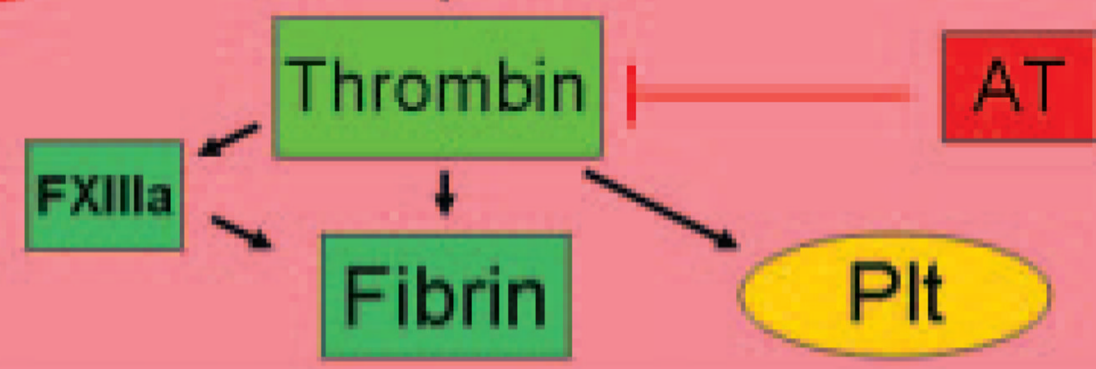

Figure 1.

Simplified version of the clotting cascade. Tissue factor (TF) and FVIIa comprise the extrinsic pathway. FXIIa, FXIa, FIXa, and FVIIIa are members of the intrinsic pathway. The common pathway is made up of FVa, FXa, and thrombin. Thrombin cleaves fibrinogen, activates FXIII, and activates platelets (Plt). The clotting cascade is regulated by three major pathways: TF pathway inhibitor (TFPI) that inhibits the TF:FVIIa complex; activated protein C (APC) that cleaves and inactivates FVa and FVIIIa; and antithrombin (AT) that inhibits thrombin and other proteases in the cascade. For simplicity only activated proteases and cofactors are shown. 


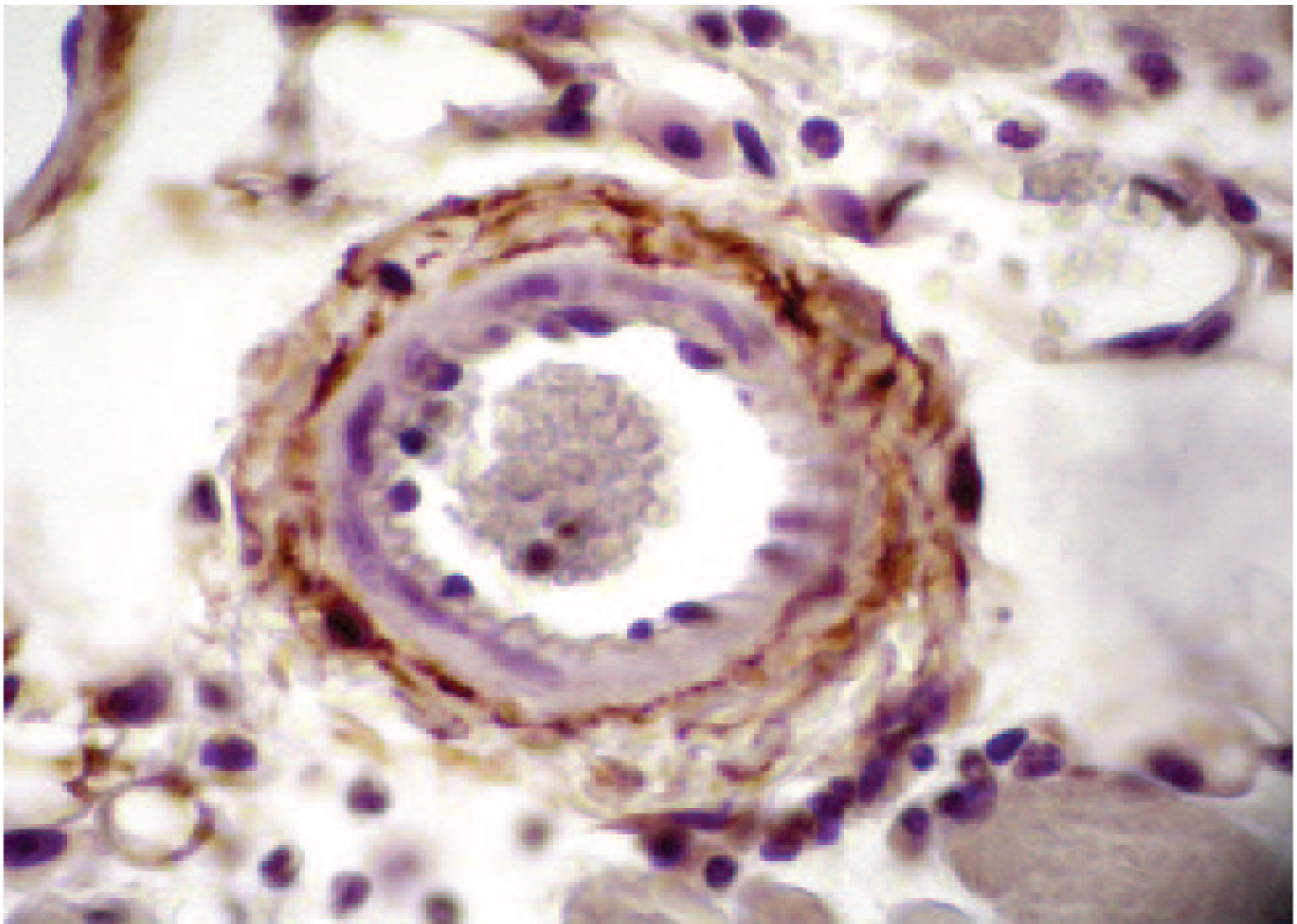

Figure 2.

Tissue factor (TF) expression in the vessel wall. TF staining (brown color) in the wall of a mouse arteriole. Original magnification $\times 400$. The picture was kindly provided by Dr. M. Hoffman, Duke University, North Carolina. 

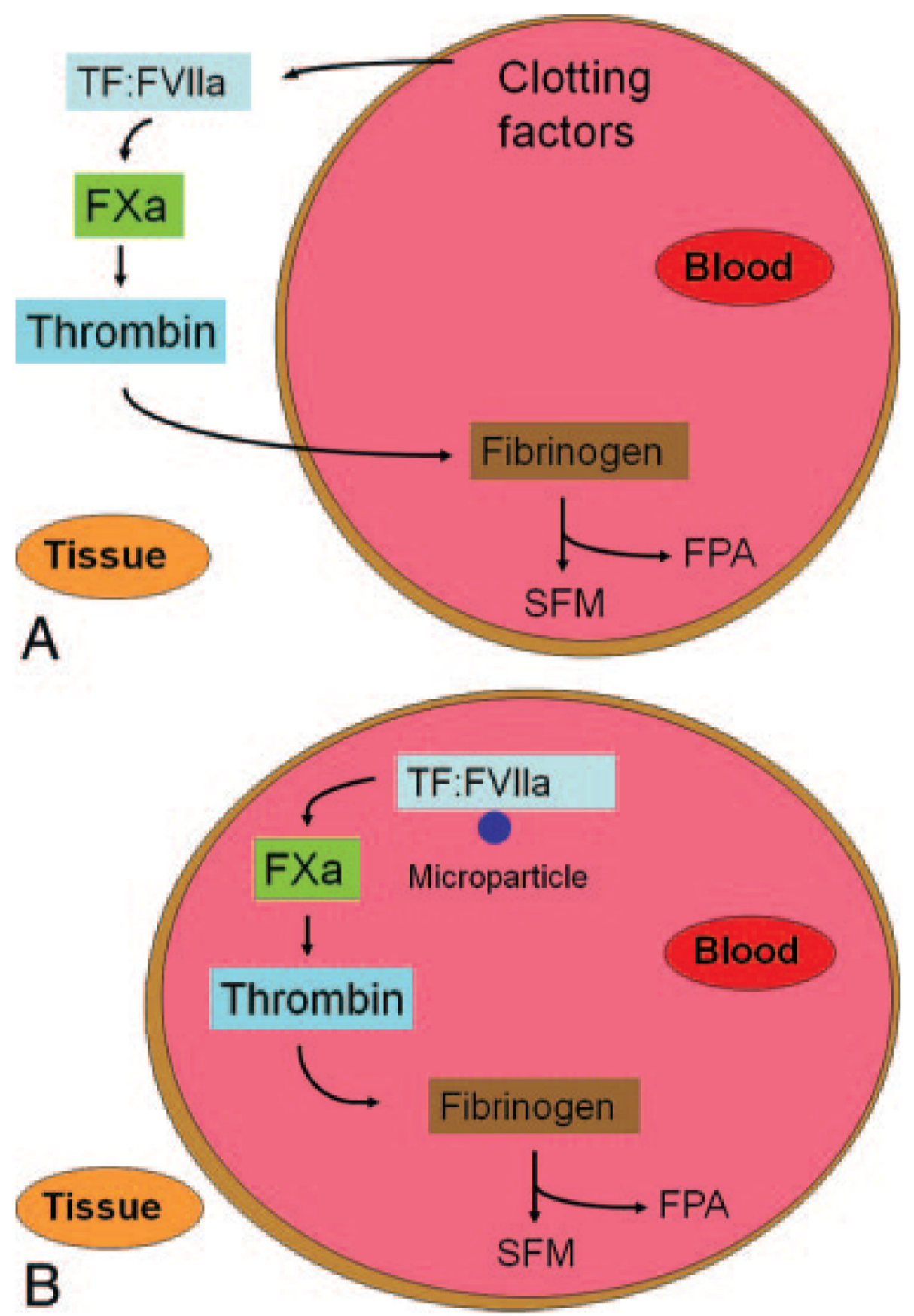

Figure 3.

Models for idling of the clotting cascade in normal individuals. (A) The extravascular tissue factor (TF) model. It is proposed that the smaller clotting factors leak into the vessel wall and this generates low levels of thrombin. Diffusion of thrombin back into the blood would allow cleavage of low levels of fibrinogen and the release of Fibrinopeptide A. Alternatively, subclinical vessel injury may expose extravascular TF and lead to the generation of low levels of TF. (B) The intravascular TF model. TF on the surface of microparticles generates low levels of FXa and thrombin. 


\section{Extrinsic Pathway Driven Clotting}

\section{Heart}

Brain

Lung

Uterus

Placenta

Testis

\section{Intrinsic Pathway Driven Clotting}

\section{Skeletal Muscle}

Joints

Low TF expression

\section{High TF expression}

Figure 4.

Model for tissue-specific hemostasis. It is proposed that the extrinsic pathway mediates hemostasis in tissues that express high levels of tissue factor (TF), whereas the intrinsic pathway mediates hemostasis in tissues that express low levels of TF. 